\title{
MEDICATION ADHERENCE IN PATIENTS WITH TYPE 2 DIABETES MELLITUS - A CROSS-SECTIONAL STUDY
}

\author{
PRATHYUSHA RANI T*, PRASHANTHI B, AYESHA AMREEN FATHIMA, AYESHA FIRDOSE, SARA NASER, \\ NAJMA BEGUM, KAUSER BEGUM
}

Department of Pharmacy Practice, Vaagdevi Institute of Pharmaceutical Sciences, Sri Indu Institutes of Pharmaceutical Sciences, Hyderabad, Telangana, India. Email: ushapharmd10@gmail.com

Received: 05 July 2019, Revised and Accepted: 19 August 2019

ABSTRACT

Objective: This study was conducted to determine the adherence of medications among type 2 diabetes mellitus (DM) patients. To evaluate adherence to therapy and study factors associated with non-adherence and adherence in patients with type II DM.

Methods: A cross-sectional, observational study was conducted for 6 months in three hospitals. A total of 200 type II diabetic patients, who were on anti-diabetic drug therapy for at least 6 months, were enrolled. Blood glucose was measured and details of drug therapy were noted. Medication adherence was assessed using the Morisky Medication Adherence Scale and adherence scores were calculated.

Results: Only 15\% had high medication adherence, while $24 \%$ had moderate and $61 \%$ had low medication adherence. 0nly $30 \%$ were having optimally controlled glycemic levels, whereas $70 \%$ were having uncontrolled glycemic levels. Medication adherence scores were lower (reflecting lower adherence) in type II patients with uncontrolled glycemic levels than those having optimally controlled glycemic levels, but this difference was not statistically significant.

Conclusion: Overall, medication adherence was low in type II diabetic patients. The study shows that to improve medication adherence, better counseling and health education of patients are required. Although several patients were adherent to therapy, adherent patients are more preferably to achieve glycemic control than nonadherent patients. Greater efforts are needed to facilitate diabetes self-management behaviors to improve patient outcomes.

Keywords: Medication adherence, Morisky Medication Adherence Scale, Type II diabetes mellitus, Therapeutic outcome.

(C)2019 The Authors. Published by Innovare Academic Sciences Pvt Ltd. This is an open access article under the CC BY license (http://creativecommons. org/licenses/by/4. 0/) DOI: http://dx.doi.org/10.22159/ajpcr.2019.v12i10.34787

\section{INTRODUCTION}

Diabetes mellitus (DM) is a chronic metabolic disorder characterized by the presence of hyperglycemia accompanied by impairment in the metabolism of carbohydrates, lipids, and proteins. DM can vary greatly, but always include defects in either secretion of insulin or response or both at some point in the course of the disease. Most patients with DM have either Type 1 DM (which is immune-mediated or idiopathic) or Type 2 DM (non-insulin dependent DM) is the most widely recognized type of DM characterized by insulin resistance, hyperglycemia, and relative insulin deficiency. Type 2 DM results from the collaboration between genetic, environmental and behavioral risk factors [1]. DM is a growing public health problem worldwide with an estimated 177 million individuals affected in 2003, 221 million by 2010 and is expected to rise to 300 million in 2025 with the highest increases in Asia and Africa [2]. By 2025, it is assessed over $75 \%$ of individuals with diabetes are accounted in low-income countries. The use of medication plays a key role in the management of T2DM. However, the effectiveness of the treatment for diabetes relies upon the degree of medication adherence towards the endorsed treatment. As per the World Health Organization (WHO), guideline adherence is up to, which degree an individual behavior; following a diet, receiving medication, and executing lifestyle changes corresponds with recommendations from the health care provider [3]. Non-adherence to medication is most basic among patients with diabetes [4]. Inadequate adherence compromises safety and prompts ineffective treatment, which ascends in mortality and morbidity rate. Medication adherence is essential for successful treatment in patients with DM results in a better outcome, for example, hemoglobin $\mathrm{A} 1 \mathrm{C}$ values, reduces the risk of hospitalization and mortality as well as the health care costs will be diminished [5].
Medication adherence to anti-diabetics were estimated using the Morisky Medication Adherence Scale (MMAS-8). Endorsement to utilize and interpret the (MMAS-8) into any languages like English, Hindi, and Urdu or any other language that comprehended by the patients was obtained by the developers. The interpretation was carried out according to the standard backward and forward method. The (MMAS- $8^{\odot}$ ) comprises of eight inquiries intended to assess medication adherence. The initial 7 are Yes/No inquiries while the last question is replied with a 5-point Likert scale. One point each is given in a sentence dependent on the appropriate response. In the initial 7 questions, one point is given for each "NO" answer except question number 5 where one point is given for the "YES" answer. For thing number 8, one point is given for "never/rarely" in a while and zero points are given for all the time. The complete MMAS- ${ }^{\odot}$ score is the summation of the scores for the 8 questions. The all-out MMAS- $8^{\odot}$ score is the summation of the scores for the 8 questions. The full-scale score got ranged from 0 to 8 . In this assessment, patients with a full-scale score of MMAS- $8^{\odot}<6$ were considered nonadherent.

Estimation of medication adherence rates to anti-diabetic revealed variable results, but indicated a strong tendency toward poor medication adherence [6,7]. The medication adherence to oral anti-diabetics were defined according to the WHO ATC Classification System, including the defined daily dose classification, and finally provided by the proportion of days covered (PDC) with an observation period of 12 months. In the literature, the PDC in the recommended measure that provided rather conservative, but precise estimates and was calculated as follows: the number of days of oral antidiabetic medication supplied between the first prescription (defined as index date) and the last date of the 1 -year perception period following the index date was isolated by the 
total days of the interval (365 days) for every patient. The defined daily doses for diabetes drug classes recommended by the WHO were used to determine the number of days supplied for each oral antidiabetic drug class 20 .

\section{METHODS}

\section{Study setting}

Participants were recruited from three public health hospitals in South India for 6 months (i.e., July-December). These hospitals were specifically chosen because they differ in terms of the characteristics of the patients they serve and the geographical regions in which they are situated. The variability of the sites provided a broad range of patients with DM.

\section{Study respondents and data collection}

This was a cross-sectional and observational study to evaluate DM, diabetes with other commodities, diabetes-related knowledge, demographic and clinical factors with medication adherence among patients with DM using the MMAS-8. The approach we followed in this study was similar to that used by other scholars who investigated the relationship between medication adherence and other factors [8-11]. The present research approach was based on using medication adherence as an outcome while using demographic, clinical, psychological factors, antidiabetic therapy, glycemic status as independent variables. The tools used in this study have been previously used by other investigators [8-15]. The study included a convenience sample of the adult population. Participants were recruited from three hospitals, while waiting to be seen by their health care providers. A sample of 200 diabetic patients who reported as type 1 and 2 diabetes, availability of a medical record at the diabetic clinic; a history of at least 1 year of DM; currently being under medical care for diabetes; and finally willingness to participate in this study are included in the study. Patients with physical and/or mental conditions that could interfere with the participant's ability to understand and/ or answer questions in any of the scales used were excluded. Diabetesrelated knowledge has also been reported to influence both medication adherence and glycemic control [18].

\section{Statistical methods}

Data recorded were entered in Microsoft Excel version 2018. Data were expressed in actual numbers, mean \pm standard deviation, and percentage; t-test was used to compare the mean between the two groups. The probability $\mathrm{p}<0.05$ was considered as statistically significant.

\section{RESULTS}

A total of 200 type II diabetic patients was included and analyzed. The mean age of the sample, a male was $58.8( \pm 10)$ (range $=35$-86) years. Most of the participants were females 126 (63\%). Patients reported an average of $(130 ; 65 \%)$ of additional illnesses. Hypertension (155; $77.5 \%)$, hypothyroidism $(17 ; 8.5 \%)$, coronary artery disease (CAD)

\section{Morisky 8-Item Medication Adherence Questionnaire}

\begin{tabular}{|c|c|c|}
\hline Question & $\begin{array}{l}\text { Patient } \\
\text { Answer } \\
\text { (Yes/No) }\end{array}$ & $\begin{array}{l}\text { Score } \\
\mathrm{Y}=1 \text {; } \\
\mathrm{N}=0\end{array}$ \\
\hline \multicolumn{3}{|l|}{ Do you sometimes forget to take your medicine? } \\
\hline \multicolumn{3}{|l|}{$\begin{array}{l}\text { People sometimes miss taking their medicines for reasons other } \\
\text { than forgetting. Thinking over the past } 2 \text { weeks, were there any } \\
\text { days when you did not take your medicine? }\end{array}$} \\
\hline \multicolumn{3}{|l|}{$\begin{array}{l}\text { Have you ever cut back or stopped taking your medicine } \\
\text { without telling your doctor because you felt worse when } \\
\text { you took it? }\end{array}$} \\
\hline \multicolumn{3}{|l|}{$\begin{array}{l}\text { When you travel or leave home, do you sometimes forget to } \\
\text { bring along your medicine? }\end{array}$} \\
\hline \multicolumn{3}{|l|}{ Did you take all your medicines yesterday? } \\
\hline \multicolumn{3}{|l|}{$\begin{array}{l}\text { When you feel like your symptoms are under control, do you } \\
\text { sometimes stop taking your medicine? }\end{array}$} \\
\hline \multicolumn{3}{|l|}{$\begin{array}{l}\text { Taking medicine every day is a real inconvenience for some } \\
\text { people. Do you ever feel hassled about sticking to your } \\
\text { treatment plan? }\end{array}$} \\
\hline \multirow{7}{*}{$\begin{array}{l}\text { How often do you have difficulty remembering to take all your } \\
\text { medicine? } \\
\text { - A. Never/rarely } \\
\text { _B. Once in a while } \\
\text { _C. Sometimes } \\
\text { _D. Usually }\end{array}$} & & $\begin{array}{l}A=0 \\
B-E=1\end{array}$ \\
\hline & & \\
\hline & & \\
\hline & & \\
\hline & & \\
\hline & & \\
\hline & Total score & \\
\hline \multicolumn{3}{|c|}{$\begin{array}{l}\text { Scores: }>2=\text { low adherence } \\
1 \text { or } 2=\text { medium adherence } \\
0=\text { high adherence } \\
\text { Morisky DE, Green LW, Levine DM. Concurrent and predictive validity of a self-reported measure of medication adherence. } \\
\text { Med Care. } 1986 ; 24: 67-74 \text {. }\end{array}$} \\
\hline
\end{tabular}


(34; $17 \%)$ and stroke $(25 ; 12.5 \%)$ were the most frequently reported additional illnesses in the study sample. Patients reported an average of $44(22 \%)$ of Monotherapy and $156(78 \%)$ of combination therapy of anti-diabetic medications and $2.3 \pm 0.9$ different medications taken daily and taking $\geq 4$ medications regularly. The mean duration of DM reported by the patients was $9.5 \pm 21.4$ years. The mean duration of glycemic status, the controlled level is $60(30 \%)$ and the uncontrolled level is $140(70 \%)$ was reported by the patients. The mean of insulin use to controlled the glycemic level was $135(67.5 \%)$ reported by the patients and the mean of glucose random blood sugar (GRBs) reported by the patients was 286.7. The demographic data along with details of the duration of treatment, current anti-diabetic drug therapy, and medication adherence were recorded. Their GRBs was measured by Accucheck active Glucometer. Demographic and clinical characteristics of participants are presented in (Table 1).

\section{Adherence to ant diabetic medication}

A total study of 200 diabetic patients only $15 \%$ were adherent to the anti-diabetic medication while $24 \%$ had moderate and $61 \%$ had low medication adherence based on the total MMAS score presented in (Table 2).

\section{Reported adherence and beliefs}

As the study was conducted in 200 patients only a few of them were highly adherent and most of them said that they forgot to take medicines when away from home and/or traveling of about (56\%); 81\% complained of inconvenience and difficulty in adhering to medication plan; $67 \%$ said they just forget to take medicines.

Antidiabetic medication adherence between diabetics, according to controlled and uncontrolled glycemic levels

We found that only $30 \%$ were having controlled blood glucose, whereas $70 \%$ were having uncontrolled blood glucose despite being on drug

Table 1: Sociodemographic characteristics of respondents

\begin{tabular}{ll}
\hline Patient characteristics & Value \\
\hline Patients with type II diabetics & 200 \\
Age in years (mean) & \\
$\quad$ Male & $58.8 \pm 10.9$ \\
$\quad$ Female & $56.5 \pm 12.5$ \\
Gender (mean) (\%) & $74(37)$ \\
$\quad$ Male & $126(63)$ \\
$\quad$ Female & $9.5 \pm 21.4$ \\
Duration of treatment in years (mean) & $2.3 \pm 0.9$ \\
Number of medications (mean) & \\
Mean blood glucose (mg/DL) & 286.7 \\
GRBs & $60(30)$ \\
Glycemic status (\%) & $140(70)$ \\
Controlled & \\
Uncontrolled & $44(22)$ \\
Antibiotic therapy (\%) & $156(78)$ \\
Monotherapy & \\
Combination & $135(67.5)$ \\
$\quad$ Yes & $65(32.5)$ \\
$\quad$ No & \\
Presence of chronic disease (\%) & $130(65)$ \\
Yes & $70(35)$ \\
$\quad$ No & \\
\hline n=200, GRBs: Glucose random blood sugar &
\end{tabular}

Table 2: Level of medication adherence among type II diabetic patients

\begin{tabular}{ll}
\hline Medication adherence level (as per MMAS) & Percentage $\mathbf{n = 2 0 0}$ \\
\hline Low adherence (score $>2)$ & $61(122)$ \\
Moderate adherence $($ score 1 or 2$)$ & $24(48)$ \\
High adherence (score 0) & $15(30)$ \\
\hline
\end{tabular}

MMAS: Morisky Medication Adherence Scale 1 therapy. On subgroup analysis, the MMAS score was higher in the controlled group in comparison with the uncontrolled group, but this difference was not statistically significant (Table 3).

\section{DISCUSSION}

The findings of the study suggest that medication adherence was low and addresses the issue of non-adherence-among type II diabetic patients. Worldwide studies using various research assessment instruments and systematic reviews have addressed issues of poor medication adherence among diabetes patients.

In this study, medication adherence was assessed by using MMAS-8 a validated scale. The scale is designed to facilitate the identification of barriers and behaviors associated with adherence to medication. Only $15 \%$ had high medication adherence while $24 \%$ had moderate and $61 \%$ had low medication adherence. It was observed that many patients forgot to take medicines with them while traveling. Some of them stopped to take medicines on their own because they believed that their diabetes was under control. Others felt it was difficult to stick to a prescribed treatment plan and stopped to take medication. Hypertension $(77.5 \%)$, CAD $(34 ; 17 \%)$ and stroke $(25 ; 12.5 \%)$ are the most frequent comorbidities recorded in the study. Most of them were in the combination therapy (78\%) study in Study in south Nigeria show that $70.3 \%$ of the patients were on combination therapy and it was reflected the necessity of intensive control of blood glucose level [16]. The findings are comparable to several Indian studies documented poor adherence to antidiabetic medication. Ahmad et al. observed that Adherence to medications in type 2 DM was unsatisfactory and resulted in wastage of medications and less than the optimal outcomes. The determinants of medication nonadherence were age, medication information scores, and the nearness of comorbidities. The recognized degree of adherence in this study was like past investigation findings. In this study poor Medication adherence among the type $2 \mathrm{DM}$ patients was observed, which has to be improved for the better therapeutic outcome. The medication knowledge should be improved mostly in patients with comorbidities [17]. One of the biggest challenges for health care providers today is addressing the continued needs and demands of individuals with chronic illnesses like diabetes [19]. The importance of regular follow-up of diabetic patients with the health care provider is of great significance in averting any long term complications. Studies have reported that strict metabolic control can delay or prevent the progression of complications associated with diabetes [20]. Results of huge randomized trials including patients with type 1 diabetes or recently recognized or set up type 2 diabetes demonstrate that control of glycemia delays the onset and slows the progression of microvascular complications, including nephropathy, retinopathy, and neuropathy [21]. About $25 \%$ of patients with type 2 $\mathrm{DM}$ as of now have microvascular complications at the time of diagnosis recommending that they have had the disease for over 5 years at the time of diagnosis [22]. Some of the Indian studies revealed very poor adherence to treatment regimens due to poor attitude towards the disease and poor health literacy among the general public [23]. In a few studies, it has been concluded that structured education to patients by a pharmacist by applying pharmaceutical care activities has shown a significant improvement in medication adherence behavior, supporting the interventional educational role of the pharmacist [24]. To improve medication adherence as we should assure that patients achieve continuing education about the disease and medications, provide the

Table 3: Comparison of medication adherence score between diabetic patients with controlled and uncontrolled glycemic levels

\begin{tabular}{llc}
\hline Variable & $\begin{array}{l}\text { Glycemic status } \\
\text { controlled uncontrolled }\end{array}$ & p-value \\
\hline $\begin{array}{l}\text { MMAS total } \\
\text { scores (Mean } \pm \text { SD) }\end{array}$ & $30.5 \pm 17.3-70.5 \pm 40.4$ & 0.00001 \\
\hline${ }^{*}$ p-value between-group comparisons by in 1. SD: Standard deviation &
\end{tabular}


patient with written and oral information, and encouraging patients to visit their health care providers regularly [25].

\section{CONCLUSION}

Our findings showed that medication adherence was low in type II diabetic patients. As the current prescribing plan resulted in glycemic control in less than half of the patients, the majority are still not meeting the recommended blood glucose target. This is mainly due to poor medication adherence with prescribed therapy and poor knowledge and practice of self-management behaviors. There is a need for regular monitoring of patient adherence to medication and initiate steps to improve the adherence to antidiabetic medication. Therefore, counseling and health education of the patients related to medication adherence and strategies to increase drug availability need to be improved. Finally, improving knowledge of diabetic patients about their illness and self-management will positively influence their medication adherence and therapeutic outcome.

\section{ACKNOWLEDGMENT}

The authors acknowledge the hospital management for providing facilities for conducting this study.

\section{AUTHORS' CONTRIBUTION}

All the authors have contributed equally to the design, development, review, and finalization of the contents of the manuscript.

\section{CONFLICT OF INTEREST}

The authors confirm that this article content has no conflicts of interest.

\section{REFERENCES}

1. Dolores SD, editor. Greenspan's Basic and Clinical Endocrinology. $9^{\text {th }}$ ed. Ch. 17. New York: McGraw-Hill Medical; 2011.

2. Perry M. Early detection of Type 2 diabetes: The role of the community nurse. Br J Community Nurs 2001;6:176-9.

3. WHO. Adherence to Long Term Therapies, Time for Action. Geneva: World Health Organization; 2003. p. 221.

4. Cramer JA. A systematic review of adherence with medications for diabetes. Diabetes Care 2004;27:1218-24.

5. Campbell SM, Roland MO, Middleton E, Reeves D. Improvements in quality of clinical care in english general practice 1998-2003: Longitudinal observational study. BMJ 2005;331:1121.

6. Vermeire E, Hearnshaw H, Van Royen P, Denekens J. Patient adherence to treatment: Three decades of research. A comprehensive review. J Clin Pharm Ther 2001;26:331-42.

7. Horne R, Weinman J. Patients' beliefs about prescribed medicines and their role in adherence to treatment in chronic physical illness. J Psychosom Res 1999;47:555-67.

8. Mann DM, Ponieman D, Leventhal H, Halm EA. Predictors of adherence to diabetes medications: The role of disease and medication beliefs. J Behav Med 2009;32:278-84.

9. Al-Qazaz HKh, Hassali MA, Shafie AA, Sulaiman SA, Sundram S, Morisky DE, et al. The eight-item morisky medication adherence scale MMAS: Translation and validation of the Malaysian version. Diabetes
Res Clin Pract 2010;90:216-21.

10. Al-Qazaz HK, Hassali MA, Shafie AA, Syed Sulaiman SA, Sundram S. Perception and knowledge of patients with Type 2 diabetes in Malaysia about their disease and medication: A qualitative study. Res Social Adm Pharm 2011;7:180-91

11. Fawzi W, Abdel Mohsen MY, Hashem AH, Moussa S, Coker E, Wilson $\mathrm{KC}$, et al. Beliefs about medications predict adherence to antidepressants in older adults. Int Psychogeriatr 2012;24:159-69.

12. Zyoud SH, Al-Jabi SW, Sweileh WM, Morisky DE. Relationship of treatment satisfaction to medication adherence: Findings from a crosssectional survey among hypertensive patients in Palestine. Health Qual Life Outcomes 2013;11:191.

13. Zyoud SH, Al-Jabi SW, Sweileh WM, Wildali AH, Saleem HM, Aysa HA, et al. Health-related quality of life associated with treatment adherence in patients with hypertension: A cross-sectional study. Int J Cardiol 2013;168:2981-3.

14. Sweileh WM, Ihbesheh MS, Jarar IS, Sawalha AF, Abu Taha AS, Zyoud SH, et al. Differences in medication adherence, satisfaction and clinical symptoms in schizophrenic outpatients taking different antipsychotic regimens. Curr Drug Saf 2011;6:285-90.

15. Sweileh WM, Ihbesheh MS, Jarar IS, Sawalha AF, Abu Taha AS, Zyoud $\mathrm{SH}$, et al. Antipsychotic medication adherence and satisfaction among palestinian people with schizophrenia. Curr Clin Pharmacol 2012;7:49-55

16. Yusuff KB, Obe O, Joseph BY. Adherence to anti-diabetic drug therapy and self management practices among Type-2 diabetics in Nigeria. Pharm World Sci 2008;30:876-83.

17. Ahmad NS, Ramli A, Islahudin F, Paraidathathu T. Medication adherence in patients with Type 2 diabetes mellitus treated at primary health clinics in Malaysia. Patient Prefer Adherence 2013;7:525-30.

18. Choudhry NK, Shrank WH, Levin RL, Lee JL, Jan SA, Brookhart MA, et al. Measuring concurrent adherence to multiple related medications. Am J Manag Care 2009; 15:457-64.

19. Whitmer RA, Karter AJ, Yaffe K, Quesenberry CP Jr. Selby JV. Hypoglycemic episodes and risk of dementia in older patients with Type 2 diabetes mellitus. JAMA 2009;301:1565-72.

20. de Galan BE, Zoungas S, Chalmers J, Anderson C, Dufouil C, Pillai A, et al. Cognitive function and risks of cardiovascular disease and hypoglycaemia in patients with Type 2 diabetes: The action in diabetes and vascular disease: Preterax and diamicron modified release controlled evaluation (ADVANCE) trial. Diabetologia 2009;52:2328- 36

21. Stumvoll M, Goldstein BJ, van Haeften TW. Type 2 diabetes: Principles of pathogenesis and therapy. Lancet 2005;365:1333-46.

22. ADVANCE Collaborative Group, Patel A, MacMahon S, Chalmers J, Neal B, Billot L, et al. Intensive blood glucose control and vascular outcomes in patients with Type 2 diabetes. N Engl J Med 2008;358:2560- 72 .

23. Hermansen K, Mortensen LS, Hermansen ML. Combining insulins with oral antidiabetic agents: Effect on hyperglycemic control, markers of cardiovascular risk and disease. Vasc Health Risk Manag 2008;4:561- 74

24. Adepu SP, Sam S, Omankuttan C, Ramnath KV, Yashashwini Y. Assessment of pharmacist mediated education on medication adherence behavior in Type 2 diabetes mellitus patients in the south Indian rural population. Int J Pharm Pharm Sci 2008;10:39-43.

25. Rabba AK, Algiers WS, Ahmed NJ, Alkharfy KM. Medication adherence in Type2 diabetic patients: A study in Saudi Arabia. Int J Pharm Pharm Sci 2007;9:247-50. 